\title{
Bilateral choanal polyps originating from the inferior concha
}

\author{
Nurdoğan Ata $\odot$, Kayhan Öztürk
}

Department of Otorhinolaryngology, KTO Karatay University School of Medicine, Medicana Konya Hospital, Konya, Turkey

A 33-year-old man presented with bilateral nasal obstruction and snoring for the past 4 years. The patient had undergone septoplasty and inferior turbinate radiofrequency treatment 3 years ago owing to nasal obstruction, but his symptoms had not improved. Endoscopic examination revealed bilateral inferior concha hypertrophy and total obstruction of the choana by conchachoanal polyps.

Computed tomography (CT) of the nasal paranasal sinuses revealed bilateral inferior concha hypertrophy with choanal obstruction with polyps (Figure 1. a, b). The patient elected to undergo endoscopic inferior turbinectomy and choanal polyp excision. An endoscopic excision of the polyp and partial inferior turbinectomy with preserving lateral mucosa of the inferior nasal concha were performed. Bleeding control was performed with bipolar cautery, and surgicel (surgicel ${ }^{\circledR}$ Ethicon, Somerville, USA) was placed on the concha incision surface.

Intraoperative endoscopic and macroscopic examinations of the extracted specimen revealed that the polyps originated from the lower turbinate (Figure 2. a, b).

Histopathologic examination identified the polypoid specimens as inflammatory polyps. The patient's postoperative period was uneventful. Two years after the surgery, he was free of symptoms, and an endoscopic examination did not detect any signs of recurrence. Written informed consent was obtained from the patient.

Choanal polyps often originate from the maxillary sinus and are called anthrachoanal polyps. If they originate from the inferior concha, they are known as conchachoanal polyps, which are extremely rare. ${ }^{1,2}$ To the best of our knowledge, there are no previously reported bilateral cases, and only a few studies have described the occurrence of unilateral conchachoanal polyps. ${ }^{1-4}$

The polyp usually originates from the tail of the inferior concha. ${ }^{2}$ An association between inferior concha mulberry hypertrophy and conchachoanal polyps has been reported in 3 cases., ${ }^{2,3}$

The symptoms caused by conchachoanal polyps are nonspecific in nature and include nasal congestion, hyposmia, runny nose, mouth breathing, and snoring. ${ }^{1}$ With the use of endoscopes in routine nasal examinations, the detection of different types of nasal pathologies has increased. ${ }^{1}$ When a choanal polyp is detected in an endoscopic examination, paranasal CT is very helpful in determining its origin and whether it is accompanied by other sinonasal pathologies. ${ }^{5}$

Endoscopic polyp excision is recommended for the treatment of conchachoanal polyps. If turbinoplasty is to be performed owing to mulberry hypertrophy of the associated inferior concha, the medial mucosa of the concha should be preserved. In addition, the concha incision surface should be electrocauterized to prevent bleeding. ${ }^{2}$

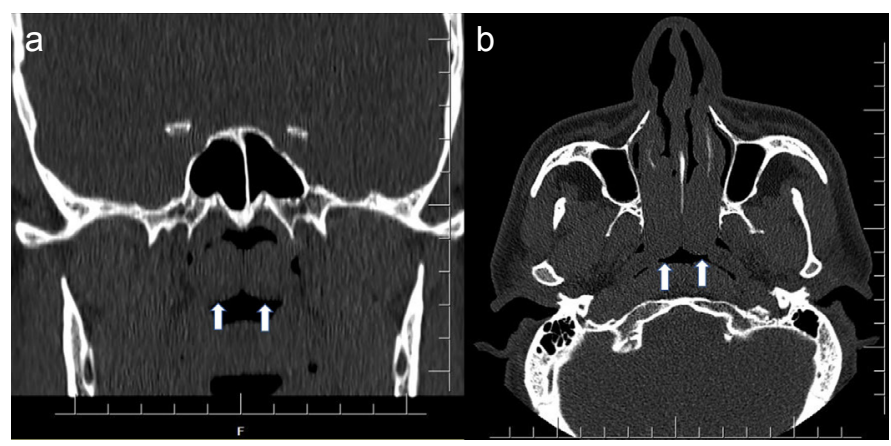

FIG. 1. a, b. Coronal and axial paranasal CT images showing bilateral conchachoanal polyps (arrows). CT: computed tomography.

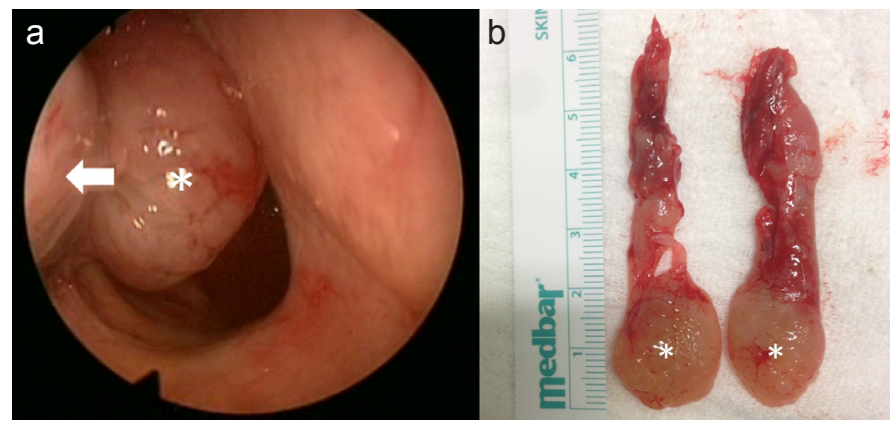

FIG. 2. a, b. Perioperative endoscopic view showing conchacoanal polyp without mulberry hypertrophy in the lower turbinate (asterisk [*] indicates the polyp, the arrow indicates the turbinate) (A). Extracted partial turbinectomy specimens with polyps $\left({ }^{*}\right)(B)$.

Address for Correspondence: Nurdoğan Ata, Department of Otorhinolaryngology, KTO Karatay University School of Medicine, Medicana Konya Hospital, Konya, Turkey

e-mail: op.dr.na@gmail.com

Received: August 22, 2020 Accepted: November 24, 2020 •DOI: 10.4274/balkanmedj.galenos.2020.2020.8.147

Available at www.balkanmedicaljournal.org

ORCID iDs of the authors: N.A. 0000-0002-0763-0852; K.Ö. 0000-0001-8141-0965.

Cite this article as:

Ata N, Öztürk K. Bilateral choanal polyps originating from the inferior concha. Balkan Med J. 2021;38(2):137-138.

Copyright@Author(s) - Available online at http://balkanmedicaljournal.org/ 
To the best of our knowledge, this is the first reported case of bilateral conchachoanal polyps. Clinicians should bear in mind that choanal pathologies can cause nasal symptoms.

Evaluation of the posterior part of the nasal cavity with endoscopic examination and tomography of the paranasal sinus is very useful in detecting choanal pathologies.

Patient Consent for Publication: Written informed consent was obtained from patient who participated in this case.

Author contributions: Concept - N.A., K.Ö.; Design - N.A., K.Ö.; Supervision - N.A., K.Ö.; Resources - N.A., K.Ö.; Materials - N.A., K.Ö.; Data Collection and/or Processing - N.A., K.Ö.; Analysis and/or Interpretation - N.A.; Literature Review - K.Ö.; Writing N.A.; Critical Review - K.Ö.

Conflict of Interest: The authors have no conflicts of interest to declare.
Funding: The authors declared that this study has received no financial support.

\section{REFERENCES}

1. Aydil U, Karadeniz H, Şahin C. Choanal polyp originated from the inferior nasal concha. Eur Arch Otorhinolaryngol. 2008;265(4):477-479. [Crossref]

2. Ata N. Complete mulberry hypertrophy and conchachoanal polyp of inferior turbinate. J Craniofac Surg. 2015;26(8):e799. [Crossref]

3. Akduman D, Karaman M, Aydın E, Korkmaz D, Karaaslan A, Turgut S. Coincidence of conchachoanal polyp and complete mulberry hypertrophy of inferior concha. Laryngoscope. 2009;119(4):762-764. [Crossref]

4. Adhami M, Coste A, Escabasse V, Chalumeau F. The inferior turbinate, an unusual site for a choanal polyp: Two case reports and a review of the literature. Ear Nose Throat J. 2016;95:E1-4.

5. Yariktaş M, Doğru H, Döner F, Tüz M, Yasan H. Choanal polyp originating from the inferior turbinate presenting as nasal polyposis. Kulak Burun Bogaz Ihtis Derg. 2006;16(1):37-40. 